\title{
Ethics and invertebrates: a cephalopod perspective
}

\author{
Jennifer A. Mather ${ }^{1, *}$, Roland C. Anderson ${ }^{2}$ \\ ${ }^{1}$ University of Lethbridge, Lethbridge, Alberta T1K 3M4, Canada \\ ${ }^{2}$ Seattle Aquarium, Seattle, Washington 98101-4359, USA
}

\begin{abstract}
This paper first explores 3 philosophical bases for attitudes to invertebrates, Contractarian/Kantian, Utilitarian, and Rights-based, and what they lead us to conclude about how we use and care for these animals. We next discuss the problems of evaluating pain and suffering in invertebrates, pointing out that physiological responses to stress are widely similar across the animal kingdom and that most animals show behavioral responses to potentially painful stimuli. Since cephalopods are often used as a test group for consideration of pain, distress and proper conditions for captivity and handling, we evaluate their behavioral and cognitive capacities. Given these capacities, we then discuss practical issues: minimization of their pain and suffering during harvesting for food; ensuring that captive cephalopods are properly cared for, stimulated and allowed to live as full a life as possible; and, lastly, working for their conservation.
\end{abstract}

KEY WORDS: Invertebrates · Ethics $\cdot$ Cephalopods · Animal pain · Animal suffering

\section{INTRODUCTION}

Human attitudes towards and values placed on animals are both varied and differential, depending on the animal evaluated. The fundamental anthropocentrism of humans acts against consideration of invertebrates and is a major factor in the present crisis in invertebrate conservation-we are losing populations and species (New 1993). Even though they constitute $99 \%$ of all species on earth, invertebrates are not sufficiently understood or highly valued by people (Ponder 1992, Kellert 1993, Nash 2004). Our belief in a 'scala naturae', an evolutionary continuum leading inevitably to humans at its peak, is well explored by Eddy et al. (1993), who inadvertently demonstrated this anthropocentrism by their choice of animal species to be evaluated-only 3 of 30 were invertebrates. Both they and Bekoff (1994) found that animals judged to be more cognitively competent and those we could potentially bond with were presumed to be worth more consideration. Sadly, many people continue to show fear of and aversion towards invertebrates (Kellert 1993, Nash 2004). This fear tends to be centered in particular on arthropods, which make up perhaps half the animal species in the world and are mostly land animals (Hardy 1988), but humans in general seem indifferent at best to animals unlike us (Ponder et al. 2002).

\section{PHILOSOPHICAL APPROACHES}

It is useful to look at the philosophical bases of judgments about animals to see how these beliefs might affect attitudes towards and treatment of marine invertebrates. They can perhaps be grouped into 3 value systems: Contractarian/Kantian, Utilitarian, and Rights-based (Nussbaum 2001). Each system looks at animals from a different viewpoint and each would treat invertebrates differently, depending on the circumstances.

The first system, Contractarian/Kantian, is perhaps the ultimate in anthropocentrism and is based on older views, particularly those of Descartes, who said that animals were no better than automata and we ought not to consider their worth at all (quoted in Kellert 1993). This view separates us completely from the natural world, remains to some extent in Judeo-Christian 
philosophy (Bourdeau 2004), and denies what we might call dignity to animals. Essentially, according to this philosophy we can do what we like to animals; this view is fortunately no longer prevalent. The only redeeming aspect of this system is the viewpoint that our humaneness is of value to us, and that we therefore degrade or impoverish ourselves if we treat animals poorly (Rollin 1985) or ignore them. Kellert's (1997) book reflects these attitudes as he emphasizes we must encourage and develop our biophilia. He cites E. O. Wilson, defining biophilia (Kellert \& Wilson 1995) as an 'inherent human affinity for life and lifelike processes' and emphasizes the values of exploitation. Aesthetics, animals as metaphor, kinship with them, mastery and finding meaning in our relationship with them are things we can get from invertebrates.

The second system is the Utilitarian, which dictates that we should act to get the best overall consequences from our actions, and therefore that we must balance consequences for all involved. This viewpoint tends to be narrow, as it requires us to balance total pleasure and pain. This position then brings up the issue of what animals 'feel' and whether we can ignore animals such as invertebrates with little cognitive ability; it also looks at the wider view and not the value of the individual. In practice, Utilitarianism seems to supply many of the arguments for those who would value invertebrates more highly. They often point out their ecological value (Kellert 1993, New 1993) and their important role in biological diversity; for example, coral reefs are important as the backbone of a major marine ecosystem (Ponder et al. 2002). In addition, mollusks as a group are the most seriously endangered animals in North America (Nash 2004). Benkendoff (1999) takes this approach to the conservation of molluscan resources and Kellert (1993) expands on this approach by pointing out the value of invertebrates in waste decomposition, for food, as indicators of environmental quality and as sources of drugs to treat our illnesses. Presumably losses in terms of pain caused to the animals would be outweighed by our gains. This also brings up a topic that will be evaluated below how much pain and/or suffering do invertebrates endure, and in what situations?

The third philosophical system is the Rights-based one. Regan (2003) proposes that both agent and patient have value and thus the right to respectful treatment. This viewpoint focuses on the individual, and extends the rights that animals ought to have to include bodily integrity and bodily liberty, thus looking much more widely at what animals themselves are experiencing. Although it values animals proportionate to their level of awareness, it assumes that the rights of an animal are not totally dependent on its awareness and that all animals, presumably including all invertebrates, have the right to careful and respectful treatment (Regan 2003). Nussbaum (2001) suggests that we should care about an animal's life, health, bodily integrity and emotional well-being. This approach raises many difficult questions, such as whether aquariums, which deprive marine animals of their freedom, ought to exist. In its demands for rights for all animals, it leaves researchers with some difficult questions. For instance, one of my colleagues asked whether we should consider the host or the parasite, when their interests differ. And this viewpoint also requires that we understand the basic physiology of the animals themselves. How can we protect the rights of the clam, the brain coral or the euphausiid crustacean when we understand very little about their lifestyle, behavior and sensory ecology? Davis et al. (1999) point out the problem of our lack of understanding with ascidians as an example.

Since both the Utilitarian and Rights-based viewpoints emphasize that we must make some assessment of pain, suffering, pleasure and thriving in order to know how to act towards animals, it is these approaches which are the basis of our evaluation of invertebrates in order to best benefit them. Of all the marine invertebrates, the cephalopod mollusks are best studied and most highly regarded in terms of their intelligence and possible consciousness. Perhaps it is best to evaluate the following: what do we know about octopuses and squid in terms of their ability to suffer, individuality, cognitive capacity, consciousness and emotionality? Understanding them and evaluating their treatment in light of these abilities will be a place to start for the invertebrates.

\section{ASSESSMENT OF SUFFERING}

Any discussion of consideration of animals' lives has to first look at the issue of pain and suffering because these are what we want to avoid. Pain is a term coined by humans and often presumed to apply only to us; pain is a sense but one in which emotions and cognitions are heavily involved (Matlin \& Foley 1997). Merskey's (1986) definition underlines this evaluative capacity, as he defines it as 'information about actual or potential tissue damage, or interpreted in terms of such damage' to cover the central representation of pain signals. Human experiences are full of examples such as wartime wounds that are not painful until after the battle, or Pain Disorder (American Psychiatric Association 2000) that is not associated with any actual damage or is only triggered by it. Kavaliers (1988) suggests that one way to avoid the cognitive attribution is to describe the sensory information as nociception and the perceptual assumption as pain. Of course, just 
because an animal does not have the awareness of situations across time does not mean that nociceptive stimuli are not felt, and Bekoff (1994) points out that such stimuli might be less bearable (i.e. the suffering might be greater) if an animal had no rich cognitive life with which to remember the past or plan for and anticipate the future.

Stefano et al. (2002) note that the stress response system, which is present in invertebrates and vertebrates, is neuronally and endocrinologically similar in all animal phyla. They emphasize that these are normal reactions to stress or perturbation, that these shortterm adjustments are universal, and that cognitive responses are just an additional coping strategy beside the physiological ones. They give data on the immediate rise in immunocytes and later increase in opiates in mussels subjected to trauma or cold water shock, and note a similar response in leeches - pointing out that these are the same physiological changes as are seen in humans after coronary artery bypass surgery. In addition, these animals have ACTH (adrenocorticotrophic hormone) down-regulation of immunocyte activation, which is similar to that of mammals and an obvious way to reduce the intensity of 'perturbation' (Stefano et al. 2002). These responses are also situation-specific. Juvenile queen scallops Aequipecten opercularis had heart rate increases under predation threat only when on a substrate with no refuging potential (Kamenos et al. 2006). The heart rate of mussels Mytilus edulis similarly increased when they were in contact with effluent of their predator, dog whelk Nucella lapillus (Rovero et al. 1999), perhaps indicating arousal.

It is not just the physiology that is similar; animals of many phyla have behavioral responses that are consistent with pain in a human. Mather (2001) mentions that sea anemone clones have 'wars' and these cause tissue damage and withdrawal responses by the polyps. The stinging nematocysts of sea anemones also cause learned avoidance in crustaceans as well as in octopuses (Mather 2001). The latter animals use a variety of techniques to capture hermit crab prey (Boycott 1954), which themselves pick up anemones off the rocks and place them on top of their borrowed mollusk shells when exposed to chemical stimuli indicating that octopuses are in the vicinity (Ross \& Boletzky 1979). Thus, a variety of invertebrates have not only physiological but also behavioral responses to aversive stimuli. A more appropriate question than 'Do invertebrates feel pain?' (Fiorito 1986) would be: How and to what extent and in response to what stimuli (see Smith 1991, Advocates for Animals 2005) do different invertebrate species feel pain? And this, of course, must be linked to their brain structure and presumed cognitive capacity.

\section{ASSESSMENT OF LEARNING}

One necessity for the approach of evaluating ethics for invertebrates is to see animals as individuals. After years of lumping together all animals of the same species or in the same situation, scientists have once again begun to take into account the individuality of their experimental subjects (Gosling 2001), a trend that would provide a firmer basis for a rights approach to consideration of the individual animal. Bekoff (1994) points out that we ought not to evaluate octopuses, lobsters or nereid worms as a group, but as individuals. Evaluation of self-awareness by the mirror test (Gallup et al. 2002) has particularly come under fire for species lumping, as they tested only a few individuals, and then considered them representative of their species. Unfortunately, cephalopods are the only invertebrate group that has been assessed for such variation. There were striking differences in the reactions of octopuses to a standard situation, leading Mather \& Anderson (1993) to sort them into 3 personality dimensions, those of activity, reactivity and avoidance. Further work by Sinn et al. (2001) revealed developmental trends in these dimensions. Thus, early experience might shape temperament into personality in a similar process to that of vertebrates including humans (Berk 2000), a trend that was emphasized by Dickel et al.'s (2000) finding that early enrichment enhanced later behavioral variation in cuttlefish Sepia officinalis and Darmaillaq et al.'s (2006) finding of apparent early prey imprinting in the same species. Early-triggered developmental limitations (see Mather 2006 for a review) would have implications for animal welfare. Even though cephalopods live short lives (Hanlon \& Messenger 1996), what happened to an individual (perhaps in captivity) in early life could affect its adult behavioral repertoire and present a distorted view of the animal's behaviour to aquarium visitors.

Numerous studies over many years have established that octopuses can 'think' and learn as a result of feedback about consequences of their behavior. Wells (1978) and his colleagues conducted a long series of learning studies with Octopus vulgaris in Naples and found not only that they could learn but also that individual brain regions were specialized just to store either visually based or tactile learning. The ablation studies in this series suggested that octopuses store information quantitatively, as do vertebrates. Loss of half the optic lobe of the brain meant that an octopus learned, but more slowly. Cutting of the central commissure before a learned discrimination showed that they stored information first in one side of the brain and then transferred it to the other. Such bilateral brain organization is another parallel with mammals. Octopuses have not yet been proven able to learn to 
discriminate oddity (Boal 1991), although they may have a primitive understanding of quantity (see Mather 1995, for a review). Such ability to learn about the consequences of actions would mean octopuses need consideration under both the Utilitarian and the Rights-based ethical approaches.

Octopuses, despite their learning capacity, are not lab rats. Thus, Papini \& Bitterman (1991) pointed out their difficulty with the standard learning situation. An octopus would learn to make the correct response to the positive stimulus for a reward, but it would fail to make the standard $80 \%$ of these positive choices that is used as the normal criterion for learning. The ecological reason behind this may be that octopuses are short-term occupants of small home ranges in which they are generalist central place foragers (Mather 1991a). They shelter in a central 'home' and go on short-term foraging trips, return to the home indirectly and not by retracing their foraging paths (Mather 1991b). This uses spatial memory (Shettleworth 1998) and tests of direction choice have begun to be used as a test of learning in the laboratory (Boal et al. 2000). What looked at first like limitations on learning is instead a memory system nicely adapted to the octopus' natural history and one that needs to be considered when we are looking at issues of housing, confinement and feeding. Octopuses are notorious escape artists in the lab, so use of these natural movement patterns can put them at risk of dying on the lab floor (see Anderson 1997).

Learning is often seen as a simple stimulus-response association and, according to behaviorists, this does not assume any central cognitive capacity or decision-making. Some recent information about octopuses suggests quite the opposite. Exploration, defined by Hutt (1966), as extracting information from the environment, is a major force in octopus behavior, and these animals show the trio of explorationlearning-forgetting that makes learning adaptive (West-Eberhard 2003). More than that, when given a floating jar in the laboratory, octopuses initially manipulated it, then habituated to its presence over the short term. After that some began to blow the jar back and forth across their tank over the period of a week, doing what we would call play if we saw it in a mammal (Mather \& Anderson 1999). Further evaluation of this play-type behavior by Kuba et al. (2006) showed that it was confined to non-food items, did not (unlike in mammals) peak in early life and was shown most about the fifth day of testing. As octopuses are natural explorers and active at extraction of information from their environment, theorists from the Rightsbased point of view (Regan 2003) would argue that they had a right to a wide variety of stimuli or enrichment. Putting octopuses in barren tanks might bring up the problem often discussed in keeping vertebrates in captivity, that of boredom (Anderson \& Wood 2001).

One set of learning studies also brings up the issue of awareness and control of information extraction, whether an octopus has a 'central monitor' (Baars 1997 ) to evaluate situations. Sutherland (1960) (see summaries in Wells 1978, Mather 1995) wanted to evaluate the octopus as a 'simple visual system' and find its 'rules' for assessment of visual shapes. He initially varied shapes on horizontal and vertical extents and found that not only could octopuses learn this discrimination but they were, as vertebrates also are (Matlin \& Foley 1997), better at vertical versus horizontal than on obliques. Continuing to assess shape discrimination, he tried ratio of edge to area as a dimension and octopuses could learn that one too. As they could also discriminate between figures rotated 90 degrees and by an internally reduplicated pattern of black and white bars (octopuses cannot perceive color), they seemed to have no simple visual assessment rule. Muntz (1970) devised a pair of complex shapes that could not be discriminated by any of the 6 simple shape processing rules and concluded that the octopuses were not using a single or simple rule for encoding. They were rather figuring out what features of the stimulus they should pay attention to. This variety of information extraction and assessment would obviously factor in to any evaluation of what Bekoff (1994) calls the richness of cognitive life for the animals involved.

\section{ASSESSMENT OF AWARENESS}

Until Griffin (2001) challenged animal behavior researchers to think about the subjective content of animal minds, the area was unstudied, and even now it is both the most difficult aspect of animal behavior to contemplate and the most difficult from which to draw conclusions. What do animals know about themselves, and what do they know about other individuals, both of their own species and others? These questions obviously factor into our care and treatment of any animal but they are most difficult to answer when we cannot even contemplate tenuous parallels between ourselves and them, as we might for mammals. Bekoff \& Sherman (2004) suggest we can evaluate a continuum of animal selves, from self-referencing to self-awareness and self-consciousness. They argue that an animal's place on this continuum would be dictated more by the behavioral ecology of a species than by its brain size or phylogenetic location, which would suggest that the solitary octopus might be a less informative species to test than the more social squid. 
Self-referencing is a matching of a target individual to oneself, not necessarily by conscious decisions. The capacity of knowing what oneself is would have to be present in order to accept or reject potential mates as the right species or the right sex, something which is essential for survival. At present we have pitifully little information about how octopuses carry on this process, though somewhat more information about other cephalopods. Octopuses of the California sibling species Octopus bimaculoides and $O$. bimaculatus, which are visually separable only with difficulty by humans, reject potential mates of the other species while accepting $O$. hummelincki from Florida (Wodinsky pers. comm.). Sepia officinalis cuttlefish females given a choice of males in a Y-maze chemical cues test did make clear choices but preferred not the larger male, as expected, but one that had recently mated (Boal 1998). Sepioteuthis sepioidea squid exchanged typical male or female skin patterns to indicate sex and status. Young adult males sometimes produced a 'stripe' or 'flicker' display to a conspecific of the wrong sex, to be answered by an agonistic 'zebra'; by the time they were adults, they did not make this mistake (J. A. Mather unpubl.). All this suggests self-referencing and assignment of self to species and sex.

Self-awareness is the discrimination of oneself from others and one's own possessions from theirs. Since octopuses do not defend territories, they cannot be said to have this sense of 'mine,' but their foraging strategies clearly argue for a non-possessive version of this capacity. When an octopus went foraging, it easily returned home and did not repeat coverage of an area it had hunted in during the last few days (Mather $1991 \mathrm{~b})$. If diverted from its homeward path, an octopus could still return by a detour, suggesting a primitive spatial map. The decision whether to return home to consume a prey item or to eat it locally in hiding was only significantly dictated by the distance to homeperhaps the octopus knew 'how far it was to go'. All these pieces of evidence suggest a monitoring of one's position in space and relative position to home that would probably qualify them for this capacity.

Self-consciousness, a sense of one's own body as self and thinking about one's actions in relation to others, is the highest of Bekoff \& Sherman's (2004) 3 levels of self-cognizance. Gallup et al's (2001) mirror test has been used as the acid test of an animal's self-awareness of its own body and thus self. An animal is given a mark on its face, unbeknownst to itself, and allowed to look into a mirror. If it touches or otherwise manipulates the spot after seeing it in the mirror, it is assumed to have self recognition. So far, only primates and perhaps porpoises (who have the problem of not having manipulative arms) have passed this test. R. C. Anderson \& J. A. Mather (unpubl.) gave the mirror test to several octopuses, who increased their activity and produced a variety of color patterns but gave no irrefutable evidence that they 'knew it was themselves'. Bekoff \& Sherman (2004) mention 2 problems that need consideration here. Despite years of lab testing learning with visual stimuli (e.g. Wells 1978) and showing excellence in visual processing, octopuses in the wild are not heavily dependent on visual information and may not 'care about' their visual image in a mirror. Second, while octopuses did respond, we have no idea what these asocial animals would do if they visually recognized conspecifics or themselves.

More evidence for self-consciousness - deception is emphasized in Guzeldere et al.'s (2002) discussion of levels of deception. While deception clearly results in misleading or confusing information, it can be produced on many different levels. Thus, animals with concealing camouflage patterns or colors, such as the dorid nudibranch mollusks and crustacean kelp crabs, deceive without 'planning' to do so. A higher level of deception would be shown if the animal produced this concealment by altering its appearance at the right time and in response to the appropriate target, an ability well known in cephalopods including the octopus (Mather 2004). However, there is no proof that this is anything other than reflexive action; cuttlefish have countershading skin patterns that are in fact reversed when the animal is turned upside down (Messenger 2001), so no awareness is involved.

Deception that is intended to mislead and is planned by the individual involved would fit Bekoff \& Sherman's (2004) level of self-consciousness as well as Guzeldere et al's (2002) highest level of deception. Bekoff \& Sherman's (2004) suggestion that behavioral ecology would play a role in the evolution of this behavior makes sense here; the solitary octopus is unlikely to engage in much behavioral manipulation of conspecifics. A better subject is the Caribbean reef squid Sepioteuthis sepioidea, which spends all its life in small groups (Moynihan \& Rodaniche 1982). The males indicate status to each other by exchanging zebra skin displays. The display intensity is usually an honest signal of resource holding power except in one situation (Mather 2006). When a male and female are about to mate, a sub-adult male often rushes in and challenges the paired male, who breaks off his courtship to return the challenge and chase the intruder away. In these cases, the intensity of the subadult male's zebra display is often greater than that of the higher-status courting male. Such deception about one's ability is relatively common in courting and competing animals as it only pays off to be relatively honest. Whether the intruder has a higher level of deception and knowingly manipulates the display will not be known until lab testing allows stimulus manipulation. 


\section{ETHICAL IMPLICATIONS}

Regardless of whether one takes a Utilitarian or a Rights-based approach, cephalopods demand an evaluation of our values of and ethics toward them. The practical aspects of 3 situations, i.e. harvesting for food, displaying in captivity, and conservation of invertebrates, will be the subject of this section of the paper.

There are profound ethical implications of aspects of harvesting marine animals, including cephalopods. Millions of cephalopods are harvested each year for human consumption (Roper et al. 1984) and for use as bait to catch fish (Paust 1988). Fewer cephalopods are collected live for public and private aquariums and by shell collectors. We would hope that all marine animals are harvested by humans in such a way as to minimize pain and suffering but, sadly, that is not so. Even socalled higher marine animals such as fish are thrown live into dry holds of harvest ships to die of asphyxiation, while little or no concern is given to invertebrates unless they need to be kept alive. In light of the physiological indicators of distress found in invertebrates (Stefano et al. 2002), all harvested invertebrates, including cephalopods, should ideally be quickly and humanely euthanized before being prepared for human consumption. This would also prevent stress-induced degradation of food quality and taste, a Utilitarian argument.

While there is little consideration for any poikilotherm animal during harvest, the necessity for consideration of the welfare of invertebrates is increasing in research laboratories, where scientists are being held accountable for the ethical treatment of their animals. Scientists have long been held responsible for keeping 'higher' vertebrates in the laboratory under good conditions and treating them ethically (Shapiro 1999). Now several regulatory agencies (Canadian Council for Animal Care 1993) have realized that at least some invertebrates, especially cephalopods, should be given similar considerations. Moltschaniwskyj et al. (2007) review the requirements for different cephalopod groups and Boyle (1991) gives a basic guide for care and management. In order to have their results published in many scientific journals, researchers have to sign an affidavit stating that their research subjects were treated ethically (Canadian Council for Animal Care 1993).

Considerations of care can limit subject selection for research. Most cephalopods held for testing are octopuses and cuttlefish, as open ocean nautiluses and squid require much more advanced husbandry techniques than a normal research lab can provide. Nautiluses require a changing regime of water temperatures that match their diurnal depth migrations in the wild (Carlson 1987) and squid require large darkwalled tanks designed to prevent their hitting the walls (Hanlon et al. 1983). In contrast, Wells (1961) said that octopuses had outstanding virtues as experimental animals since they are intelligent, the right size, easy to keep in laboratories and to feed and have a large brain with acute sensory organs to supply it with information. Octopuses have high visual acuity (Hanlon \& Messenger 1996) in spite of their inability to discriminate colors (Messenger 2001). But these practical limitations of research to only a few species may give us a distorted view of 'the' cephalopod.

Why should these particular invertebrates be subject to ethical consideration when we keep them in captivity? Bekoff (1994) found that animals judged cognitively competent merited more consideration, and the evidence presented in this paper surely proves the cognitive ability of cephalopods. Their lens-based eyes may focus our interest, as it gives us a point of commonality with an animal otherwise so alien to us (Anderson \& Wood 2001), as the ancient lineages that lead to octopuses and humans diverged more than a billion years ago (Wray et al. 1996). It is also because of the octopuses' eyes and the manipulative capacity of their arms, so similar to ours, that they are first among the invertebrates in terms of popular support for their ethical treatment.

Given all the information presented earlier in this paper, we believe that octopuses held in laboratories should be given ethical treatment. What does this treatment comprise? They need a tank to live in that is large enough to allow them free movement, but more important is a varied and rich environment with tasks to accommodate their natural exploratory tendencies (Anderson \& Wood 2001). Cuttlefish Sepia spp. and squid require a proportionately larger tank than octopuses since they swim by explosive jet propulsion (Hanlon \& Messenger 1996). There should be natural or novel objects in the tank that octopuses can explore and play with (Mather \& Anderson 1999) and there should be a den or materials such as rocks with which to construct a den (Anderson \& Wood 2001), as octopuses sleep (D. A. Meisel et al. unpubl.) in a protected area. Food, whether live or dead, should be high quality both for selection by the animals and for enhancement of water quality. Although frozen food is adequate for octopus health (Anderson 1987, 1997), occasional live food should be presented to stimulate natural predatory activity and for enrichment, though this brings up the issue of suffering by the intended prey. For people holding cephalopods in labs away from the ocean and unable to obtain marine organisms for food, research shows that octopuses will eat many live freshwater fish and crustaceans and gain adequate nutrition from them (Anderson \& Wood 2001). Live prey also stimulates natural predatory responses such as the webover method of capturing food described by Mather (1998). Water quality and dissolved oxygen must remain high 
as cephalopods excrete ammonia (see also Boyle 1991). Experiments should be designed and conducted to avoid injury and any possible suffering, which is difficult given our current lack of knowledge of exactly what constitutes pain and suffering for these animals.

Appropriate housing for any animal will also be that which minimizes injury. The sides of any tank must remain smooth since octopuses, squid and cuttlefish can swim into the sides of the tank (Hanlon et al. 1979, Wood 1998) and develop injuries and infected sores from the skin damage on their posterior ends (they normally swim backwards). The skin damage can lead to bacterial infections and death. Housing must also be appropriate in terms of inclusion of conspecifics; solitary octopuses may injure or kill each other if housed together (Mather 2001), but schooling squid should be kept together. Similarly, many individuals of crustacean species can be kept in an aquarium with sufficient shelter, but territorial stomatopods may need to be kept singly or require wide spacing (Caldwell \& Dingle 1975).

During the last several decades, zoos and aquariums have come to realize, perhaps belatedly, that animals kept in captivity also need environmental enrichment for their well-being (Seidensticher \& Forthman 1998). Early zoos and aquariums tried to show as many animals as possible; hence, their exhibits were frequently small and bare to permit easy viewing, cleaning and sterilization. Now we have come to realize that captive animals, including invertebrates, need environmental enrichment both for their health and for the education of the public and to meet the increased expectations of visitors to zoos and aquariums.

What is environmental enrichment? Shepherdson (1998) defines it as an animal husbandry principle that aims to improve the quality of captive animal care necessary for the best possible physiological and psychological health by identifying and providing the necessary environmental stimuli. Mench (1998) points out the importance of exploratory behavior: ' ... housing systems should incorporate enrichment that allows animals to engage in their species-typical patterns of information gathering'. Since octopuses explore their environment (Mather \& Anderson 1999) and often escape from small tanks, this is particularly important for them.

There are 5 reasons why enrichment is needed for all captive animals based on their behavior in captivity, 3 of which are closely related. The first of these is to maintain healthy activity levels, the second to alleviate the effects of confinement, and the third to change a deviant behavior back to a normal one. In other words, captive animals should be physically and mentally healthy (and see Regan 2003, for an animal's right to be so). In the wild, octopuses spend $25 \%$ of their time acquiring and preparing food (Mather 1988) while at the same time avoiding predators. In a captive environment, food and mates (if available) are often obtainable without much effort and predation pressure is usually non-existent. This environmental change can leave captive animals without the activities that normally take up their time.

We know that intelligent animals and social ones get bored (Wemelsfelder 1993). Some common symptoms of boredom resulting from close confinement in an animal are: repetitive route retracing, constant attempts to break out of its confinement or abnormal sleep or rest patterns. However, in a captive animal boredom is usually exhibited by destructive behavior, which can be directed against its enclosure, against the contents of its enclosure or against itself, its tank mates or its keeper. The simple solution of enlarging an animal's enclosure often brings its behavior back to normal. What might a bored octopus do? A case was described by Anderson (2005) where a presumably bored octopus attacked her tank repeatedly by moving rocks around the tank, scratching the glass, blowing gravel from the bottom, biting through the nylon ties holding the bottom water filter together and breaking it into pieces which were found by a frustrated keeper in the morning. Such an animal kept in captivity obviously needed enrichment to keep her occupied and avoid such destructive activities. Environmental enrichment has also proved beneficial for common cuttlefish Sepia officinalis, as living in a complicated environment increased the learning ability of the animals (Dickel et al. 2000).

A fourth (and Utilitarian) reason for enrichment of the lives of animals in aquariums is to meet the expectations of the public. The design of zoo and aquarium enclosures must be considered from the public's perspective. Barnacles and limpets may settle easily on smooth black plastic surfaces (boat owners know that barnacles can grow on pretty well anything), but aquarium visitors do not see black plastic as 'real' and are more comfortable seeing them on surfaces that resemble rocky shores. Likewise, since knowledge of the intelligence of octopuses is expanding (Tennesen 1999, Anderson 2005), the public expects more enrichment for them. Aquariums are emphasizing enclosures that resemble natural habitats, for the comfort and expectations of their customers as well as for the comfort of the animals (Baker 1999). Popular sea horses and sea dragons kept in captivity should have sea grasses and kelp to rest on and camouflage with, likewise cuttlefish that bury (see Mather 1986) should have suitable smooth-grained sand for the comfort of the animals as well as the public.

The fifth reason for enrichment, which follows from the Rights-based moral approach, is to prepare ani- 
mals for reintroduction to the wild; a popular marine example of pressure for reintroduction is Keiko the killer whale. Reintroduced animals need to be able to cope with natural environmental conditions and hazards (Miller et al. 1998), such as daily or seasonal variations in temperature and food supply, predators, and parasites. They may need to be able to cope with competition among cohorts, or to migrate at certain times of the day or year, and they must be able to avoid predators. Hatchery-reared salmon are notoriously unaware of predators and suffer higher than normal predation loss because of this naiveté (Brown \& Day 2002). Some salmon hatcheries have tried placing a predator in with the salmon to make them better at predator avoidance when they are released into the sea (Berejikian 1995). We have few examples from the cephalopod group, but there is one example of an octopus being released to the wild with successful results (Anderson 2000).

The routine release of a captive-reared giant Pacific octopus Enteroctopus dofleini from the Seattle Aquarium afforded an opportunity to make observations on the survival and behavior of the released animal (Anderson 2000) and showed the reaction of the public to it. There are few such long-term observations of $E$. dofleini in the wild (but see Hartwick et al. 1978). Ursula was a small giant Pacific octopus when she was donated to the Seattle Aquarium. As she got larger she was placed on display at the Aquarium in a larger octagonal tank. She was released after being fed live crabs for several weeks prior to being returned to the ocean. She was growing too large for a tank to easily contain her and the release gave her a chance to reproduce in the wild (see the Rights-based approach for her 'right' to live a full life and reproduce).

In addition to being watched by Aquarium customers, her release was covered by $\mathrm{TV}$, radio and newspapers, attesting to the popularity of such an event (Anderson 2000). She was watched by divers during the release and followed for 4 mo. Remains of prey outside the den as is normal for this species (Hartwick et al. 1978) showed her to be capturing and eating normal prey items of 3 species of crabs, proving she was hunting successfully. At the time of her last sighting, there were 3 male octopuses within $100 \mathrm{~m}$ of her den. This shows the ability of the successful release of a captive-reared octopus to hunt and feed in the wild and to attract potential mates. It also shows how the public is fascinated by such releases and willing to be educated about such enrichments for the octopus and to learn about octopus natural history. Keeping these animals in captivity opened a window for the public and allowed them to imagine life in the wild.

All wild animals live in complex and dynamic environments and all have adaptations to those environ- ments (Krebs \& Davies 1993). The unspoken rule seems to be to apply enrichment only to animals thought of as social and/or intelligent and, of course, this is why it is being done by cephalopod keepers. But while the complexity of animals' cognitive lives may affect public interest in their care (Bekoff 1994), there is no reason why professionals should neglect 'simpler' animals. Cephalopods gain obvious benefits from enrichment (Anderson \& Wood 2001) but snails, cleaner shrimp and nereid worms likely would too. Until we know which animals enrichment benefits, it should also be applied to all animals. The ethics of confinement and appropriate enrichment for all species of invertebrate animals kept in captivity should be considered (Nussbaum 2001).

Perhaps the most important aspect of animal ethics is ensuring their survival in the wild (see New 1993, Cassis 1999), and our consideration of the survival of invertebrates is sadly lacking, since more invertebrates such as mollusks have become extinct in the last $200 \mathrm{yr}$ than all mammals and birds combined (Nash 2004). To date there are only a few success stories among the invertebrates. The Banff Hot Springs snail Physella johnsoni, which only lives in 5 clustered hot springs in Canada, is being protected by laws prohibiting disruptive bathing in several of these springs (Struzik 1999) and Partula taeniata snails, which are endangered on many of their endemic islands in the South Pacific, are being saved from extinction by American zoos (Pearce-Kelly et al. 1995). Of course, one of the biggest problems with ensuring that invertebrates do not become extinct is lack of knowledge about them - what the species are, where populations live and what their ecology might be. Davis et al. (1999) discuss this problem with reference to the ascidians, and the project Census of Marine Life (Myers et al. 2006) is a recent attempt to find out what animals exist in the many marine habitats before human activity directly or indirectly extinguishes them. Here, education is the key (Cassis 1999) to assuring consideration of invertebrates.

So far no cephalopods have been declared endangered, but this is probably due to a lack of knowledge rather than conservation efforts. Nautiluses are being trapped for their shells in the Philippines and Palau and are now being found in much smaller numbers than historically (Monks 2002). The recently described mimic octopus of Indonesia (Norman \& Hochberg 2005 ) is now rarely seen due to over-collection by local divers to sell for the aquarium trade (Caldwell \& Shaw 2002). However, since no one is doing any population studies on these cephalopods, they may become extinct without our realizing it. One success story, as far as preserving a cephalopod species, is the giant cuttlefish of Australia (Sepia apama). These cuttlefish migrate to one small area to mate and lay eggs and this 
area has now been declared a preserve for the continuation of the species (Bavendam 1995).

Perhaps it all comes down to education. We extend ethical consideration to mammals because they are like us, we know about and can empathize with them (Eddy et al. 1993, Bekoff 1994). Ethical consideration is being extended to the cephalopod mollusks because researchers are in the process of learning about their intelligence and cognitive abilities and making this information public (see Hanlon \& Messenger 1996). Scientists are beginning to learn about not only the scope and diversity of the marine invertebrates (Cassis 1999) but the extent to which their responses to stress are similar to ours (Stefano et al. 2002). Such knowledge of what they are and why they matter to us (Kellert 1993) will be critical to conservation of and ethical behavior toward invertebrates. Beyond this, it is obvious that education of the general public (Meehan 1995) can change the overall negative view held about invertebrates (Kim 1993). The public will begin to see that if we hold these animals in high regard and respect their existence, caring about them enriches our own lives as well as theirs.

\section{LITERATURE CITED}

Advocates for Animals (2005) Cephalopods and decapod crustaceans - their capacity to experience pain and suffering. Advocates for Animals, Edinburgh. Available at: www.advocatesforanimals.org.uk/resources/index.html

American Psychiatric Association (2000) Diagnostic and statistical manual of mental disorders, 4th edn TR. American Psychiatric Association, Washington, DC

Anderson RC (1987) Cephalopods at the Seattle Aquarium. Int Zoo Yearb 26:41-48

Anderson RC (1997) Octopus dofleini and O. rubescens: animal husbandry. In: Lang MA, Hochberg FG (eds) Proceedings of the workshop on fishery and market potential of octopus in California. Smithsonian Institution, Washington, DC, p 141-149

Anderson RC (2000) The release of a captive-reared giant Pacific octopus. Drum and Croaker 31:7-10. Available at: www.colszoo.org/internal/pastissues.htm

Anderson RC (2005) How smart are octopuses? Coral 2:44-48

Anderson RC, Wood JB (2001) Enrichment for giant Pacific octopuses: happy as a clam? J Appl Anim Welf Sci 4: 157-168

Baars BJ (1997) In the theatre of consciousness: global workspace theory, a rigorous scientific theory of consciousness. J Conscious Stud 4:292-309

Baker AJ (1999) Peso primate reserve at the Philadelphia Zoo: designing for animals and people. Annu Conf Proc Am Zoo Aquarium Assoc, p 204-209

Bavendam F (1995) Chameleon of the reef. Natl Geogr Mag Sept 1995, p 94-107

Bekoff M (1994) Cognitive ethology and the treatment of nonhuman animals: how matters of mind inform matters of welfare. Anim Welf 3:75-96

Bekoff M, Sherman PW (2004) Reflections on animal selves. Trends Ecol Evol 19:176-180

Benkendoff K (1999) Molluscan resources: their past, present and future value. In: Ponder W, Lunney D (eds) The other
99\%: the conservation and biodiversity of invertebrates. Royal Zoological Society of New South Wales, Mosman, NSW, p 316-321

Berejikian BA (1995) The effects of hatchery and wild ancestry and experience on the relative ability of steelhead trout fry (Oncorhynchus mykiss) to avoid a benthic predator. Can J Fish Aquat Sci 52:2476-2482

Berk LE (2000) Child development, 5th edn. Allyn \& Bacon, Boston, MA

Boal J (1991) Complex learning in Octopus bimaculoides. Am Malacol Bull 9:75-80

Boal J (1998) Social recognition using chemical cues in cuttlefish (Sepia officinalis Linnaeus, 1758). J Exp Mar Biol Ecol 230:183-192

Boal JG, Dunham AW, Williams KT, Hanlon RT (2000) Experimental evidence for spatial learning in octopuses. J Comp Psychol 114:246-252

Bourdeau P (2004) The man-nature relationship and environmental ethics. J Environ Radioact 72:9-15

Boycott BB (1954) Learning in Octopus vulgaris and other cephalopods. Pubbl Stn Zool Napoli 25:67-93

Boyle PR (1991) The care and management of cephalopods in the laboratory. Universities Federation for Animal Welfare, Ennisfield Print and Design, London

Brown C, Day RL (2002) The future of stock enhancements: lessons for hatchery practice from conservation biology. Fish Fish 3:79-94

Caldwell RL, Dingle, H (1975) Ecology and evolution of agonistic behavior in stomatopods. Naturwissenschaften 62 : 214-222

Caldwell RL, Shaw CD (2002) Mimic octopuses: Will we love them to death? The Cephalopod Page. Available online at: www.thecephalopodpage.org/mimic.php

Canadian Council for Animal Care (1993) Guide to the care and use of experimental animals, Vol 1, 2nd edn. CCAC, Ottawa, ON

Carlson BA (1987) Collection and aquarium maintenance of Nautilus. In: Saunders WB, Landman NH (eds) Nautilus: the biology and paleobiology of a living fossil. Plenum Press, New York, p 563-578

Cassis G (ed) (1999) Workshop: putting invertebrates on the agenda: opportunities for the future. In: Ponder W, Lunney D (eds) The other 99\%: the conservation and biodiversity of invertebrates. Royal Zoological Society of New South Wales, Mosman, NSW, p 437-45

Darmaillacq AS, Chichery R, Shashar N, Dickel L (2006) Early familiarization overrides innate prey preference in newlyhatched Sepia officinalis cuttlefish. Anim Behav 71: 511-514

Davis AR, Roberts D, Ayre DJ (1999) Conservation of sessile marine invertebrates: You do not know what you have got until it is gone. In: Ponder W, Lunney D (eds) The other $99 \%$ : the conservation and biodiversity of invertebrates. Royal Zoological Society of New South Wales, Mosman, NSW, p 316-312

Dickel L, Boal JG, Budelmann BU (2000) The effect of early experience on learning and memory in cuttlefish. Dev Psychobiol 36:101-110

Eddy TJ, Gallup GG Jr, Povinelli DJ (1993) Attribution of cognitive states to animals: anthropomorphism in comparative perspective. J Soc Issues 49:87-101

Fiorito G (1986) Is there 'pain' in invertebrates? Behav Process 12:383-388

Gallup GG Jr, Anderson JR, Shillito DJ (2002) The mirror test. In: Bekoff M, Allen C, Burghardt GW (eds) The cognitive animal: empirical and theoretical perspectives on animal cognition. MIT Press, Cambridge, MA, p 325-333 
Gosling SD (2001) From mice to men: What can we learn about personality from animal research? Psychol Bull 127: $45-86$

Griffin DR (2001) Animal minds. University of Chicago Press, Chicago, IL

Guzeldere G, Nahmias E, Deaner R (2002) Darwin's continuum: building blocks of deception. In: Bekoff M, Allen C, Burghardt GW (eds) The cognitive animal: empirical and theoretical perspectives on animal cognition. MIT Press, Cambridge, MA, p 353-362

Hanlon RT, Messenger JB (1996) Cephalopod behaviour. Cambridge University Press, Cambridge

Hanlon RT, Hixon RF, Hulet WH, Yang WT (1979) Rearing experiments on the California market squid, Loligo opalescens Berry, 1911. Veliger 21:428-431

Hanlon RT, Hixon RF, Hulet WH (1983) Survival, growth, and behavior of the loliginid squids Loligo plei, Loligo pealei, and Loliguncula brevis (Mollusca: Cephalopoda) in closed seawater systems. Biol Bull 165:637-685

Hardy TN (1988) Entomophobia: the case for Miss Muffet. Bull Entomol Soc Am 34:64-69

Hartwick EB, Thorarinsson G, Tulloch L (1978) Methods of attack by Octopus dofleini (Wülker) on captured bivalve and gastropod prey. Mar Behav Physiol 5:193-200

Hutt C (1966) Exploration and play in children. Symp Zool Soc Lond 18:61-81

Kamenos NA, Calosi P, Moore PG (2006) Substratum-mediated heart rate responses of an invertebrate to predation threat. Anim Behav 71:809-813

Kavaliers M (1988) Evolutionary and comparative aspects of nociception. Brain Res Bull 21:923-932

Kellert SR (1993) Values and perceptions of invertebrates. Conserv Biol 7:845-855

Kellert SR (1997) Kinship to mastery: biophilia in human evolution and development. Island Press, Washington, DC

Kellert SR, Wilson EO (eds) (1995) The biophilia hypothesis. Island Press, Washington, DC

Kim KE (1993) Biodiversity, conservation and inventory: why insects matter. Biodivers Conserv 2:191-215

Krebs JR, Davies NB (1993) An introduction to behavioural ecology, 3rd edn. Blackwell Science, London

Kuba M, Byrne RA, Meisel DV, Mather JA (2006) Exploration and habituation in Octopus vulgaris. J Comp Psychol 120: 184-190

Mather JA (1986) Sand digging in Sepia officinalis: assessment of a cephalopod mollusc's 'fixed' behavior pattern. J Comp Psychol 100:315-320

Mather JA (1988) Daytime activity of juvenile Octopus vulgaris in Bermuda. Malacologica, 29:69-76

Mather JA (1991a) Foraging, feeding and prey remains in middens of juvenile Octopus vulgaris (Mollusca: Cephalopoda). J Zool 224:27-39

Mather JA (1991b) Navigation by spatial memory and use of visual landmarks in octopuses. J Comp Physiol A 168: 491-497

Mather JA (1995) Cognition in cephalopods. Adv Stud Behav 24:316-353

Mather JA (1998) How do octopuses use their arms? J Comp Psychol 112:306-318

Mather JA (2001) Animal suffering: an invertebrate perspective. J Appl Anim Welf Sci 4:151-156

Mather JA (2004) Cephalopod skin displays: from concealment to communication. In: Oller K, Greibel U (eds) Evolution of communication systems. MIT Press, Cambridge, MA, p 193-213

Mather JA (2006) Behaviour development: a cephalopod perspective. Int J Comp Psychol 19:98-115
Mather JA, Anderson RC (1993) Personalities of octopuses (Octopus rubescens). J Comp Psychol 107:336-340

Mather JA, Anderson RC (1999) Exploration, play and habituation in octopuses (Octopus dofleini). J Comp Psychol 113:333-338

Matlin MW, Foley HJ (1997) Sensation and perception, 4th edn. Allyn \& Bacon, Needham Heights, MA

Meehan C (1995) Education: improving the image of invertebrates. Vic Nat 112:60-63

Mench JA (1998) Environmental enrichment and the importance of exploratory behavior. In: Shepherdson DL, Mellen JD, Hutchins M (eds) Second nature: environmental enrichment for captive animals. Smithsonian Institution Press, Washington, DC, p 30-46

Merskey H (1986) Classification of chronic pain: description of chronic pain syndromes and definitions of pain terms. Pain (Suppl) 3:1-225

Messenger JB (2001) Cephalopod chromatophores: neurobiology and natural history. Biol Rev 76:473-528

Miller B, Biggins D, Vargas A, Hutchins M and 5 others (1998) The captive environment and reintroduction: the black footed ferret as a case study with comments on other taxa. In: Shepherdson DL, Mellen JD, Hutchins M (eds) Second nature: environmental enrichment for captive animals. Smithsonian Institution Press, Washington, DC, p 97-112

Moltschaniwskyj NA, Hall K, Lipinski M, Marian JEAR and 9 others (2007) Ethical considerations when using cephalopods as experimental animals. Rev Fish Biol Fish 17 (in press)

Monks N (2002) The perils of the pearly nautilus. The Cephalopod Page. Available at: www.thecephalopodpage. org/nautcon.php

Moynihan MH, Rodaniche AF (1982) The behaviour and natural history of the Caribbean reef squid Sepioteuthis sepioidea with a consideration of social, signal and defensive patterns for difficult and dangerous environments. Adv Ethol 125:1-150

Muntz WRA (1970) An experiment on shape discrimination and signal detection in Octopus. Q J Exp Psychol 22:82-90

Myers RA, Matsuda H, Stefansson G (2006) Future of marine animal populations. Census of Marine Life. Available at: www.coml.org/descrip/fmap.htm

Nash S (2004) Desperately seeking charisma: improving the status of invertebrates. Bioscience 54:487-494

New TR (1993) Angels on a pin: dimensions of the crisis in invertebrate conservation. Am Zool 33:623-630

Norman MD, Hochberg FG (2005) The 'mimic octopus' (Thaumoctopus mimicus n.gen.et.sp), a new octopus from the tropical Indo-West Pacific (Cephalopoda: Octopodidae). Molluscan Res 25:57-70

Nussbaum MC (2001) Animal rights: the need for a theoretical basis. Harv Law Rev 114:1506-1549

Papini MR, Bitterman ME (1991) Appetitive conditioning in Octopus cyanea. J Comp Psychol 105:107-114

Paust BC (1988) Fishing for octopus; a guide for commercial fishermen. Alaska Sea Grant Rep No 88-3. University of Alaska, Fairbanks, AK

Pearce-Kelly P, Mace GM, Clarke D (1995) The release of captive bred snails (Partula taeniata) into a semi-natural environment. Biodivers Conserv 4:645-663

Ponder WF (1992) Bias and biodiversity. Aust Zool 28:47-51

Ponder W, Hutchings P, Chapman R (2002) Overview of the conservation of Australian marine invertebrates, Ch 9. Report for Environment Australia. Australian Museum Online. Available at: www.amonline.net.au/invertebrates/ marine\%5Foverview/chapt9.html

Regan T (2003) Animal rights, human wrongs: an introduction to moral philosophy. Rowman \& Littlefield, Oxford 
Rollin BE (1985) The moral status of research animals in psychology. Am Psychol 40:920-926

Roper CFE, Sweeney MJ, Nauen CE (1984) FAO species catalog, Vol 3. Cephalopods of the world. FAO Fish Synop (125) Vol 3. FAO, Rome

Ross DM, von Boletzky S (1979) The association between the pagurid Dardanus arrosor and the actinian Calliactis parasitica. Recovery of activity in 'inactive' $D$. arrosor in the presence of cephalopods. Mar Behav Physiol 6: 175-184

Rovero F, Hughes RN, Chelazzi G (1999) Automatic recording of the radular activity of dogwhelks (Nucella lapillus) drilling mussels (Mytilus edulis). J Mar Biol Assoc UK 79: 1079-1083

Seidensticher J, Forthman DL (1998) Evolution, ecology, and enrichment: basic considerations for wild animals in zoos. In: Shepherdson DL, Mellen JD, Hutchins M (eds) Second nature: environmental enrichment for captive animals. Smithsonian Institution Press, Washington, DC, p 15-29

Shapiro L (1999) Applied animal ethics. Delmar Learning, Florence, KY

Shepherdson DJ (1998) Tracing the path of environmental enrichment in zoos. In: Shepherdson DL, Mellen JD, Hutchins M (eds) Second nature: environmental enrichment for captive animals. Smithsonian Institution Press, Washington, DC, p 1-14

Shettleworth SJ (1998) Cognition, evolution and behavior. Oxford University Press, New York

Sinn DL, Perrin NA, Mather JA, Anderson RC (2001) Early temperamental traits in an octopus (Octopus bimacu-

Editorial responsibility: Anne Berit Skiftesvik, Storebø, Norway loides). J Comp Psychol 115:351-364

Smith JA (1991) A question of pain in invertebrates. ILAR Journal 33:1-2

Stefano GB, Cadet P, Wei Z, Rialas CM and 7 others (2002) A blueprint for stress can be found in invertebrates. Neurol Lett 23:85-93

Struzik E (1999) Rare Banff snail (Physella johnsoni) an ecological barometer for hot springs. Edmonton Journal, November 27, 1999

Sutherland NS (1960) Theories of shape discrimination in Octopus. Nature 186:840-844

Tennesen M (1999) Another way of thinking - the octopus is smarter than your average invertebrate. Wildl Conserv 102:36-41

Wells MJ (1961) What the octopus makes of it; our world from another point of view. Am Sci 49:215-228

Wells MJ (1978) Octopus - physiology and behaviour of an advanced invertebrate. Chapman \& Hall, London

Wemelsfelder F (1993) Concept of animal boredom and its relationship to stereotyped behavior. In: Mason G, Rushen J (eds) Stereotypic animal behavior: fundamentals and applications to welfare. CABI, Wallingford, p $65-95$

West-Eberhard MJ (2003) Developmental plasticity and evolution. Oxford University Press, New York

Wood JB (1998) Cuttlefish husbandry, part III: How do I keep a cuttlefish? Freshw Mar Aquarium Mag 9:78-84

Wray GA, Leviton JS, Shapiro LH (1996) Molecular evidence for deep precambrial divergences among metazoan phyla. Science 274:586-573

Submitted: June 2, 2006; Accepted: December 9, 2006 Proofs received from author(s): March 6, 2007 